\title{
A CULTURAL LANDSCAPE INFORMATION SYSTEM DEVELOPED WITH OPEN SOURCE TOOLS
}

\author{
C. Chudyk ${ }^{a}$, H. Müller ${ }^{a}$, M. Uhler ${ }^{a}$, F. Würriehausen ${ }^{a}$
}

\author{
${ }^{a}$ i3mainz, Institute for Spatial Information and Surveying Technology, \\ FH Mainz, University of Applied Sciences, Lucy-Hillebrand-Straße 2, 55128 Mainz, Germany, \\ (chudyk, mueller, uhler, wuerriehausen)@geoinform.fh-mainz.de
}

\begin{abstract}
KEY WORDS: Cultural Heritage, Semantic MediaWiki, Spatial Data Infrastructure, Open Source, E-Governance, Citizen Participation, Quality Management
\end{abstract}

\begin{abstract}
:
Since 2010, the state of Rhineland-Palatinate in Germany has developed a cultural landscape information system as a process to secure and further enrich aggregate data about its cultural assets. In an open dialogue between governing authorities and citizens, the intention of the project is an active cooperation of public and private actors. A cultural landscape information system called KuLIS was designed as a web platform, combining semantic wiki software with a geographic information system. Based on data sets from public administrations, the information about cultural assets can be extended and enhanced by interested participants. The developed infrastructure facilitates local information accumulation through a crowdsourcing approach. This capability offers new possibilities for e-governance and open data developments. The collaborative approach allows governing authorities to manage and supervise official data, while public participation enables affordable information acquisition. Gathered cultural heritage information can provide incentives for touristic valorisation of communities or concepts for strengthening regional identification. It can also influence political decisions in defining significant cultural regions worth of protecting from industrial influences. The presented cultural landscape information allows citizens to influence the statewide development of cultural landscapes in a democratic way.
\end{abstract}

\section{INTRODUCTION}

\subsection{Motivation}

A crucial international policy instrument enabling stricter protection of cultural heritage was founded with the Convention Concerning the Protection of the World Cultural and Natural Heritage of UNESCO in 1972. It lists natural and cultural heritage sites of exceptional importance which are therefore necessary to preserve (UNESCO 1972). Another important policy for Europe was created in 2000, with the European Landscape Convention. It is used in several European countries as a legal framework for the protection of cultural landscapes (Council of Europe 2000). In Germany, this agreement was neither signed nor ratified as of yet because of administrative separation of cultural and environmental management, as well as due to problems arising from different state sovereignties (Marschall et al. 2007). There is no uniform legislation in cultural landscape protection - instead, different legal levels exist along with different interpretations on the subject. In addition to the inconsistent legal situation, a lack of a cultural asset inventory complicates both the definition and protection of cultural landscapes (Fehn et. al 1993). Some German states already started to build information systems to document their cultural assets. The first one, called KulturLandschaftsElementeKataster (KLEKs), has been developed and maintained by the University of Applied Sciences Neubrandenburg since 1999, and is administered for the states of Mecklenburg-Western Pomerania, Brandenburg, Saxony, Saxony-Anhalt and Thuringia (Stöckmann 2009). The state of Rhineland-Palatinate also foresaw the necessity of protecting and inventorying its cultural heritage, and developed a legal guideline within a country development program for an implementation of a statewide cultural landscape information system in 2008 (LEP IV 2008).

\subsection{Citizen Participation}

Internet and new media citizen participation models are increasing worldwide. In 2004, the European Interoperability Framework was defined (European Communities 2004) to facilitate the interoperability of services and systems. The Federal Government of Germany launched the initiative eGovernment 2.0 with the aim of connecting citizens, businesses, public authorities and other organisations (Federal Ministry of the Interior 2006). E-Governance already influences administrative processes tremendously (Jain Palvia et al. 2007). The term Public Participation Geoinformation System (PPGIS) can be used for a system with possibilities to gather geographical information (Obermayer 2008). Goodchild (2007) outlines the resulting information as Volunteered Geographic Information (VGI), whereas the process of retrieving VGI can be generally described with the term Crowdsourcing (Howe 2006). A citizen participation system can give its contributors a positive feeling of influencing democratic processes (Clift 2004). Through a PPGIS, the developed cultural landscape information system offers those benefits. It is possible to enrich existing administrative data with widespread public knowledge about cultural heritage.

\subsection{Participants of an Interdisciplinary Process}

Due to the above-mentioned variety of legal levels in cultural landscape protection and public participation, it became clear 
that an interdisciplinary process involving different authorities was inevitable. For this reason, the planning authority at the Ministry of the Interior and Sports of Rhineland-Palatinate initiated the development of a cultural landscape information system involving administrations, the public, and members from academia providing scientific support. All actors together built the advisory body (figure 1) to launch the development process for the cultural landscape information system (Ministry of the Interior, for Sports and Infrastructure of the State of RhinelandPalatinate 2010).

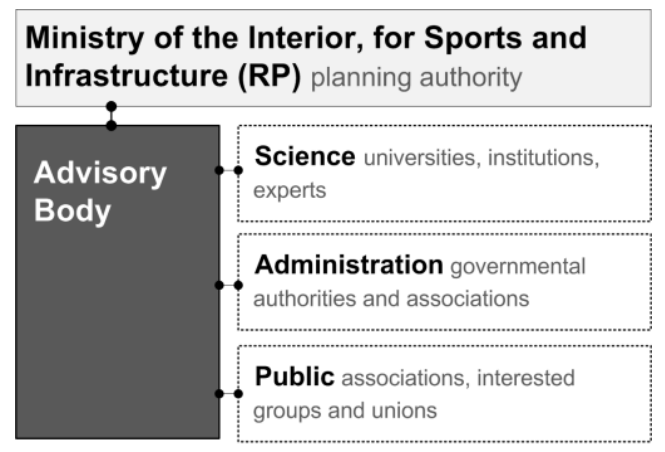

Figure 1. Members of advisory body.

In collaboration between the FIRU $\mathrm{mbH}$, the University of Trier and the i3mainz, Institute for Spatial Information and Surveying Technology at the Mainz University of Applied Science, a cultural landscape information system called KuLIS was developed to provide tools and access for cultural heritage documentation usable by both the state administration and the public. The results of this process, experiences and current developments are outlined in this article.

\section{SYSTEM DEVELOPMENT}

\subsection{System Requirements}

The main objective of KuLIS was to provide a citizenorientated and internet-accessible open platform. It would also be built following administrative and scientific regulations. Further requirements and work packages which strongly influenced the system design are defined in Table 1.

\begin{tabular}{|l|}
\hline System Requirements \\
\hline $\begin{array}{l}\text { Development of a feature catalogue for cultural assets in } \\
\text { Rhineland-Palatinate }\end{array}$ \\
\hline $\begin{array}{l}\text { Design of a spatial database to implement the catalogue } \\
\text { structure }\end{array}$ \\
\hline $\begin{array}{l}\text { Evaluation and transfer of existing data about cultural assets } \\
\text { with spatial relation into the database }\end{array}$ \\
\hline $\begin{array}{l}\text { Providing OGC conformal web map services being includable in } \\
\text { the Spatial Data Infrastructure (SDI) of Rhineland-Palatinate }\end{array}$ \\
\hline $\begin{array}{l}\text { Visualization and digitalization of cultural assets in a web } \\
\text { application interface }\end{array}$ \\
\hline $\begin{array}{l}\text { Ability to create and update information of new or existing } \\
\text { information about cultural assets with citizen participation }\end{array}$ \\
\hline $\begin{array}{l}\text { Management and validation of the provided information by } \\
\text { scientific and administrative supervisors }\end{array}$ \\
\hline $\begin{array}{l}\text { Analysis tools for further investigations and definition of } \\
\text { important cultural landscapes }\end{array}$ \\
\hline
\end{tabular}

Table 1. System requirement definition.
The requirements led to a web platform which united semantic and spatial information about cultural assets into one system, and therefore needed a combination of different web technologies. Because independence and adaptability to further development were fundamental necessities, open source technologies were used to meet these requirements.

\subsection{Feature Catalogue of Cultural Assets}

External data sources and collected cultural knowledge were integrated into a catalogue of typical landscape features of Rhineland-Palatinate. Referring to systematics of comparable catalogues (Schmidt et. al. 2008, Bavarian State Ministry of Food, Agriculture and Forestry 2001) it was developed in close coordination with the advisory body using proven engineering technologies. Similar to the catalogue of Thuringia, a hierarchical function-oriented structure was developed which enabled the classification of functional cultural landscapes. Twelve such categories were then defined (Table 2). Each category was divided into functional complexes which cluster the unique cultural features. In the lowest level one feature could be part of a feature group or a functional ensemble.

\begin{tabular}{|r|l|}
\hline No. & Functional feature categories \\
\hline 1 & Urban Settlements, Health and Social Services \\
\hline 2 & $\begin{array}{l}\text { Rural Settlements, Agriculture, Horticulture and } \\
\text { Fisheries }\end{array}$ \\
\hline 3 & Forestry \\
\hline 4 & Production and Processing of Raw Materials \\
\hline 5 & Trade, Industry and Energy Production \\
\hline 6 & Traffic, Transportation and Communication \\
\hline 7 & Government, Administration, Law, Defence and \\
\hline 8 & Military \\
\hline 9 & Education, Culture and Science \\
\hline 10 & Sport, Tourism and Recreation \\
\hline 11 & Natural Landscapes and Nature Conservation \\
\hline 12 & Intangible Goods and Associative Features \\
\hline
\end{tabular}

Table 2. Functional feature categories.

This way, the features could be stored as point, line or surface objects in a geographically and thematically precise manner. For example, a stadium could be defined as part of sports facilities in category 'Sport, Tourism and Recreation' (Table 3).

\begin{tabular}{|l|l|l|}
\hline Category & Complex & Group: Feature \\
\hline $\begin{array}{l}\text { 10. Sport, } \\
\text { Tourism and } \\
\text { Recreation }\end{array}$ & 10.1. Sport & $\begin{array}{l}\text { Sport Facilities: Golf } \\
\text { Course, } \text { Stadium, } \\
\text { Tennis Centre ... }\end{array}$ \\
\cline { 2 - 3 } & 10.2. Recreation & $\ldots$ \\
\cline { 2 - 3 } & $\ldots$ & $\ldots$ \\
\hline
\end{tabular}

Table 3. Hierarchy for feature 'stadium' in the catalogue.

The created feature catalogue and its hierarchical structure provided the foundation for the later implementations of a database structure to store and manage information about cultural assets and their relations inside of the system. 


\subsection{Existing Data Sources}

Existing data about cultural features in Rhineland-Palatinate were examined during a first evaluation. Different official databases and sources made available from state institutions, such as the Digital Landscape Model, (including e.g. all churches in Rhineland-Palatinate) and the Environmental and Cultural Heritage Data, were processed and transferred to the spatial database of the system. Based on these sources, around 59,000 individual cultural features with point, line or surface geometries could be identified and transferred into the new data structure (Boos et al 2012). Other public institutions planned to provide their related data as Open Geospatial Consortium OGC conformal Web Map Services (WMS). Services provided in the Spatial Data Infrastructure (SDI) of Rhineland-Palatinate (GeoPortal RP 2013) could be included directly into KuLIS. The considered infrastructure and its components allowing the integration of external data are described in the next paragraph.

\subsection{System Design}

Considering the need for citizen participation, a system had to be designed which permitted user enhancement of information about cultural assets by volunteers both in a thematic and geographic way. The need for an intuitive and widely accepted frontend for information display and management through different editors led to a wiki approach. As a content management system, the open source software MediaWiki allowed information creation and updating along with user management for editorial purposes (MediaWiki 2013). Furthermore, it was configurable for implementation of additional functionalities required in the project. To map the catalogue structure to the wiki and combine the content with geographical information derived from existing administrative data, a spatial data infrastructure structure was needed to provide an interface for the web mapping application, the spatial database and the server-side services. Linking information between MediaWiki and a spatial database of the mapping application was realised using a unique feature identifier ID for each cultural object. Figure 2 illustrates the infrastructure of the implemented cultural landscape information system. A more detailed description of the used components is presented in the sections below.

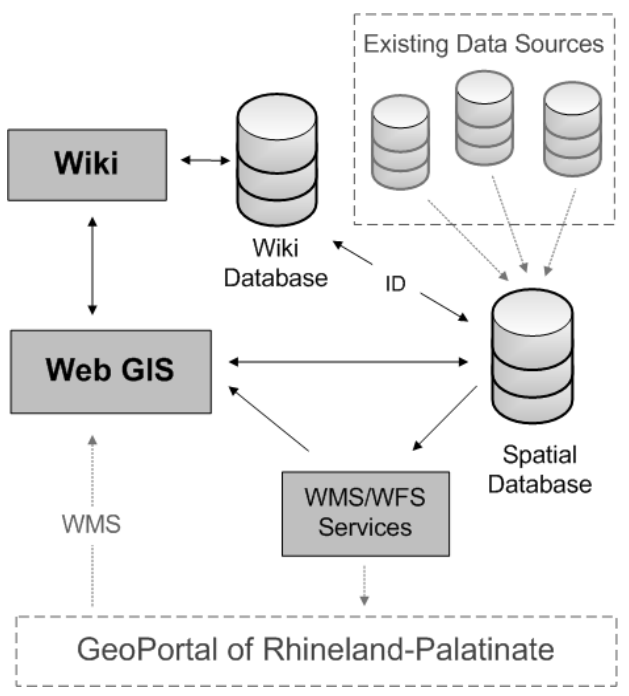

Figure 2. KuLIS System Design.
Semantic MediaWiki: For each cultural asset in the built wiki application, a wiki article with its unique feature identifier ID exists. On top of the wiki installation, the Semantic MediaWiki extension (Semantic MediaWiki 2013) is set up to enable semantic attribution for articles. By creating a new article for each cultural asset, a form enables the setting of semantic attributes.

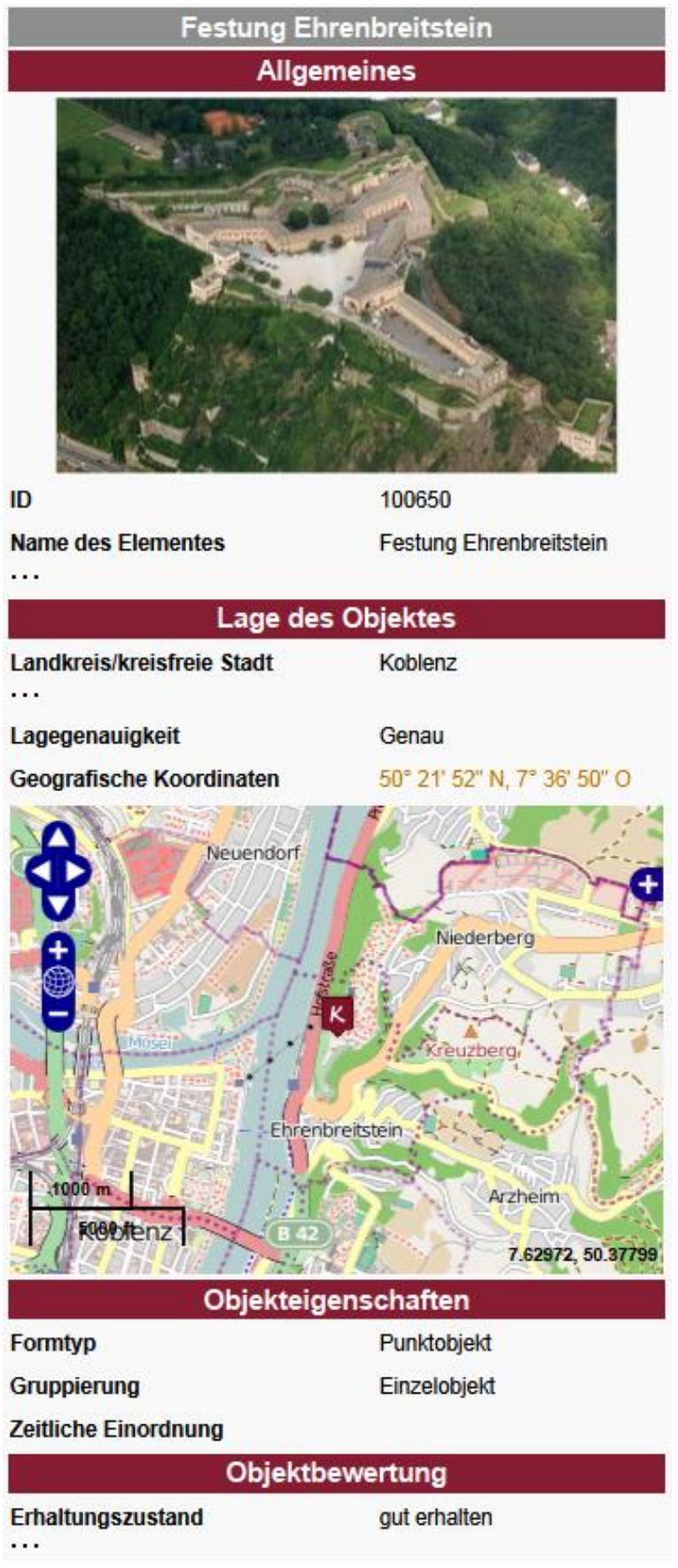

Figure 3. Profile of Ehrenbreitstein Fortress.

As a result, all features in KuLIS have a profile as shown in Figure 3. Besides general descriptions such as name and an illustration, it shows the classification in the catalogue structure in a first block ("Allgemeines"). A second block follows, with a textual and graphical description of the location as place coordinates along with its pin on a map ("Lage des Objektes"). The properties of the feature, including the geometry type (point, 
line or surface) and a chronological classification are presented in a third block of the profile ("Objekteigenschaften"). Finally, the last section presents value attributes related to cultural importance ("Objektbewertung"). These attributes are grouped into six categories and allow a four-levelled description for states of preservation (very good, good, poor and bad), rarity (unique, rare, common and very common), endangerment (high, middle, low and no endangerment), regional characteristic (very typical, typical, not very typical or atypical for region), importance (international, national, state wide, regional or local) and scenic attraction (highly perceptible, perceptible, barely perceptible and imperceptible). The semantic extension makes it possible to organise and search the features in the hierarchical structure of the feature catalogue. Intelligent querying of defined attributes of the profiles allows for the analysis and relation of content regarding cultural relevance. The extension offers further functionality, and brings the application in line with Semantic Web approaches (Berners-Lee et al 2001). Gathering attributes valuing the cultural assets and their importance especially helps to develop categorizations for cultural landscapes. With this implementation, a tool is established for later analyses and investigation of the cultural assets and their semantic relationships. In combination with the spatial information, it enhances the definition of cultural landscapes.

Spatial Data Infrastructure: All used software to set up the SDI for the system is part of the OSGeo project and therefore open source (OSGeo 2013). The location and related metadata of the cultural assets is stored backend in a PostGIS database, which includes the external data sources of the evaluation process (PostGIS 2013). A transactional WFS (WFS-T) implemented with GeoServer allows for the creation, deletion and updating of the spatial information (GeoServer 2013). For performance reasons, a Mapserver set up provides the data structured in twelve Web Map Services (WMS) according to the number of functional categories (see Table 2). With Mapbender, a Web GIS interface is implemented in the wiki frontend (see Figure 4, Mapbender 2013). It enables visualisation and digitisation of the location of cultural assets via the WMS and the WFS-T provided by the geospatial servers.

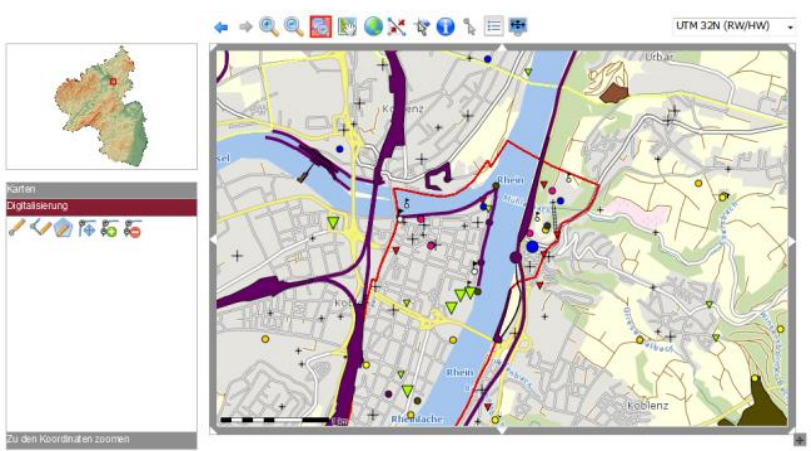

Figure 4. Web mapping application in KuLIS.

The use of a spatial database makes it possible to include information about the boundaries of municipalities, cities and counties. During the location digitisation process, the recorded coordinates can be allocated this way and a precise textual attribution of the site (e.g. county or city) enhances the profile of the cultural asset information automatically.

\subsection{Quality Management}

However, due to the fact that citizens are creating the data of an official information system, this raises the question of the administrative quality assurance role. It is for both political reasons and data-quality demands (high accuracy and consistency are needed) that an administrative authority must manage and continuously supervise the public's data acquisition. Enriching authoritative administrative data through crowdsourcing therefore is a sensitive issue; an E-Governance application requires an appropriate quality of gathered information while retaining sovereign rights of state administrations. To bring the data in KuLIS to this standard, a special information qualification process was required. With the Flagged Revisions extension of MediaWiki, additional groups with new user rights were implemented in the system. A user class 'editor,' which had the right to mark articles as read and sifted, and a user class 'reviewer,' who could validate the correctness of articles in KuLIS, were created this way. Any registered user working with the cultural landscape information system could become an 'editor,' whereas a 'reviewer' would have to be an authorized person from a state institution. Figure 5 shows the concept of the quality management of the presented system, and illustrates the different tasks of the public and state institutions. In the illustration, the flow of cultural asset information and a validation process for gathered data is shown. State institutions offer their data in the system and can validate and qualify the correctness of the combined information of public crowdsourcing and government data. The public sector is able to access the validated information.

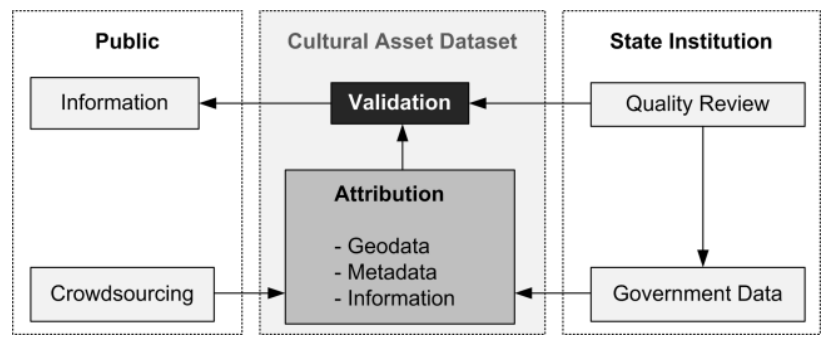

Figure 5. Administrative quality management in KuLIS

In order to configure and adapt the used open source extension to the needs of the project, flags on top of each article were placed to inform wiki frontend users about the information quality of the cultural assets. Three simple levels of flags were used, symbolised by the colours of a traffic light (see Figure 6). Newly created articles were first marked as red, read and sifted articles by authorized users as orange, and quality proofed articles by state authorization as green. By implementing this intuitive and simple highlighting function, the status of the cultural asset information is shown at any time for all features.

\begin{tabular}{|c|l|}
\hline Flag & Revision status of article \\
\hline$\Theta$ & New/Unsighted \\
\hline$\odot$ & Read and Sifted \\
\hline$\odot$ & Reviewed/Proofed \\
\hline
\end{tabular}

Figure 6. Traffic light flags in KuLIS.

This way, permanent public access to all information according to the idea of open government data and citizen participation is maintained. At the same time, the state authority requirements 
concerning clear notification of the quality assurance of the presented information are met. With this clear assignment structure, the system is designed to avoid inappropriate information acquisition in more sensitive areas such as active archaeological excavations, where citizens are not allowed to gather information independently.

\section{STATUS AND PROSPECTS}

Currently about 63,000 cultural assets (automatically or manually added) are stored in KuLIS. This large amount of such information, however, becomes a problem to categorise. The biggest challenge in the existing system is the huge amount of automatically retrieved data from government sources, because this data comes without the attributions important for characterisation. Therefore the need for a large community to help collect the required information is obvious. The developed platform offers the possibilities for a civic participation where interested users can digitise new features and enhance offered government data with additional information, as outlined in the previous chapter. The usability of the system was tested in the municipal association of Eich and through student exercises at the University of Applied Sciences in Mainz. The results led to improvements for both the digitisation process and the interface design of the cultural landscape information system. However, at the moment there is no active community making further tests of the system.

The results of these usability tests showed that the used wiki application is an intuitive and acceptable tool for cultural asset information documentation. However, it was also found that young people especially wished to use mobile devices for direct information collection, for example using their smartphones. The idea of collecting and administering data only with office desktop computers might be out of date for the younger generation. The research of further data sources for cultural asset information enrichment also showed that there is a variety of open information available on the World Wide Web which could be used to enhance the articles and profiles of the cultural assets within KuLIS.

\subsection{Location-Based Service}

The presented system also has further potential for technical development. The amount of smartphone users worldwide passed the 1 billion mark in 2012 (Ramanathan 2012) while at the same time location-based services have become common in various domains of our daily lives (Raubal 2011). Using a variety of functionalities, including photography through imbedded cameras or global positioning, modern mobile devices offer many possibilities to retrieve data directly in the operator's proximity. Regarding these facts, a modern PPGIS should also support location-based participation of users. There is an opportunity for designing a location-based service as a mobile application using the introduced cultural landscape information system. This would expand the KuLIS user base as well as be an opportunity to create an even more intuitive application with a slim interface. The already installed system to create and maintain cultural asset information would still persist in the backend and would be enhanced through further application design. This possibility again demonstrates the advantages of a system design using common open source tools and a distributed architecture.

\subsection{Linked Data}

The Semantic Web, which can be considered a next step of the World Wide Web where data can be processed directly and indirectly by machines (Berners-Lee et al. 2001) promises intelligent interoperability of information among different web applications and sources. With the Semantic MediaWiki extension, the ability to prepare KuLIS for the Web 3.0 is given. The chosen structure for the cultural asset catalogue makes it already possible to request information inside of the information system using semantic queries. For example, it is possible to search for all features in a functional category with a specific landscape importance. Other extensions such as Linked Wiki allow for the external querying of information from semantic web endpoints, and for the combination of this information with existing articles inside of KuLIS. This opportunity could support new data supplementation and enhancement by automatic data association with existing linked information. An interesting web endpoint for information enrichment in the present cultural landscape information system is DBPedia, a web project processing structured content from Wikipedia into interlinked semantic structures (Bizer et al. 2009). For example, DBPedia makes it possible to retrieve an extensive amount of articles highlighting existing currently relevant cultural assets. By querying for the name of a cultural object or looking for articles in a buffer around a location (stored as a pair of coordinates), it is possible to gain new information. Moreover, references to further sources can be guided by intelligent linking. The preparation of knowledge for relations of articles and attributes inside of the system can be provided as a web service endpoint, or directly interlinked through semantic platforms such as DBPedia.

\section{CONCLUSION}

Cultural landscapes consist of an extreme variety of features, with such variability stemming from their geographic as well as semantic characteristics. This fact presents a challenge for new developments using an aggregate system combined from distributed software modules. The presented system as a combination of current web tools combining semantic and spatial information in a public participation geoinformation system meets this challenge. Developing such an information system for cultural landscapes using exclusively open source tools is not only possible, but also enables the chance to use state of the art technologies for further development.

Outlining the implementations in this work shows that KuLIS offers promising possibilities to fulfill the complex requirements of a state administrative controlled PPGIS. The use of open source tools, used and maintained by a wide community, made it possible to adaptively change requests during the system development. Whereas common wiki implementations only work with point geometries, the power of spatial analysis and visualization is added to the system through a spatial data infrastructure. The combination of local and semantic attributes makes interlinking with other sources using the semantic web possible, and will be more important as the number of interlinkable sources grow in the future. The presented solution provides a modern platform based on open source technologies, enabling citizen participation. This approach can promote transparence and acceptance of administrative actions within a society. 


\section{REFERENCES}

\section{References from Journals:}

Bizer C., Lehmann J., Kobilarov G., Auer S., Becker C., Cyganiak R., Hellmann S. 2009: DBpedia - A

Crystallization Point for the Web of Data. Journal of Web Semantics: Science, Services and Agents on the World Wide Web, Issue 7, pp. 154-165

Fehn K., Schenk W. 1993: Das historischgeographische Kulturlandschaftskataster - eine Aufgabe der geographischen Landeskunde, Berichte zur deutschen Landeskunde 67(2), pp. 479-488

Goodchild M.F. 2007: Citizens as sensors: the world of volunteered geography. GeoJournal 69 (4), pp. 211-221

Marschall E., Werk K. 2007: Die Europäische Landschaftskonvention. Ziele, Inhalt sowie ihre derzeitige landschaftspolitische Bedeutung in Deutschland. Natur und Recht, 29 (11), pp. 719-722

Obermayer N. J. 1998: The Evolution of Public Participation GIS, Cartography and GIS, Vol. 25 (2), pp. 65-66

\section{References from Books:}

Berners-Lee T., Hendler J., Lassila O. 2001: The Semantic Web: a new form of Web content that is meaningful to computers will unleash a revolution of new possibilities, Scientific American, 284 (5), pp. 34-43

Boos S., Müller H., Würriehausen F. 2012:

Zusammenwirken öffentlicher und privater Akteure zur Dokumentation von Kulturlandschaft mit SemanticWebTools, Angewandte Geoinformatik 2012, pp. 636-645

Raubal M. 2011: Cogito Ergo Mobilis Sum: The Impact of Location-based Services on Our Mobile Lives. SAGE Publications Ltd. The SAGE Handbook of GIS and Society, Chapter 9, pp. 159-175

\section{References from Other Literature:}

Bavarian State Ministry of Food, Agriculture and Forestry 2001: Historische Kulturlandschaft. Materialien zur Ländlichen Entwicklung, Munich, Bavaria, Germany, Vol. 39

Council of Europe 2000: European Landscape Convention. ETS. 176, Strasbourg, France

European Communities 2004: European Interoperability Framework for Pan-European eGovernment Services version 1.0, Luxembourg, 2004.

Federal Ministry of the Interior 2006: eGovernment 2.0, the Programme of the Federal Government, Berlin 2006
Jain Palva S.C., Sharma S. S. 2007: E-Government and E-Governance: Definitions/Domain Framework and Status around the World, ICEG

Ministry of the Interior, for Sports and Infrastructure 2010: Kulturlandschaften in Rheinland-Pfalz, Mainz, Rhineland-Palatinate, Germany

Schmidt C., Meier H.-H. 2008: Kulturlandschaft Thüringen, Vol. 2-3, University of Applied Sciences Erfurt, Thuringia, Germany

Stöckmann M. 2008: Exposee zu KLEKs, Institut für Umweltgeschichte und Regionalentwicklung e.V., Universiyt of Applied Sciences Neubrandenburg, Mecklenburg-Western Pomerania, Germany

References from websites:

Clift S. L. 2004: E-Government and Democracy: Representation and Citizen Engagement in the Information Age, report prepared for United Nations UNPAN/DESA, www.publicus.net/articles/cliftegov democracy.pdf (21 March 2013)

GeoPortal RP 2013: GeoPortal of Rhineland-Palatinate, www.geoportal.rlp.de (25 March 2013)

GeoServer 2013: Official webpage of GeoSever project, geoserver.org (25 March 2013)

Howe J. 2006: The Rise of Crowdsourcing, WIRED magazine, Issue 14.06, www.wired.com/wired/archive/ 14.06/crowds.html (21 March 2013)

Mapbender 2013: Official wiki of Mapbender project, www.mapbender.org/Mapbender_Wiki (25 March 2013)

MapServer 2013: Official webpage of MapServer project, www.mapserver.org (25 March 2013)

MediaWiki 2013: Official web page of Mediawiki project, www.mediawiki.org/wiki (25 March 2013)

OSGeo 2013: Official webpage of OSGeo project, www.osgeo.org (25 March 2013)

PostGIS 2013: Official webpage of PostGIS project, www.postgis.org (25 March 2013)

Ramanathan V. M. 2012: Worldwide Smartphone Users Cross 1 Billion Mark: Report. International Business Times, www.ibtimes.com (17 June 2013)

Semantic MediaWiki 2013: Semantic Extension for MediaWiki, semantic-mediawiki.org (05 April 2013)

UNESCO 1972: Convention Concerning the Protection of the World Cultural and Natural Heritage. http://whc.unesco.org/en/175/ (14 March 2013) 